\title{
Observed and projected changes in rainfall extremes in the Metropolitan Area of São Paulo
}

\author{
Jose A. Marengo ${ }^{1, *}$, Maria C. Valverde ${ }^{1,2}$, Guillermo O. Obregon ${ }^{1}$ \\ ${ }^{1}$ Earth System Science Center, National Institute for Space Research (CCST/INPE), Rodovia Presidente Dutra km 40, \\ 12630-000 Cachoeira Paulista, São Paulo, Brazil
}

${ }^{2}$ Urban and Environmental Engineering (UEE), Federal University of ABC (UFABC), Santo André, 09210-170 São Paulo, Brazil

\begin{abstract}
Changes in rainfall extremes and flooding are becoming more frequent in many countries, particularly in large cities where people and assets are concentrated. In the Metropoli$\tan$ Area of the city of São Paulo (MASP) region, heavy or extreme precipitation events have important effects on society. Flash floods and landslides, associated with intense, but often brief, rainfall events, may be the most destructive of extreme events. Observations since the mid-1930s in the MASP region have shown significant increases in total and heavy rainfall and decreases in light rain. This was probably due to natural climate variability, but with some signals of the urbanization effect, especially during the last $40 \mathrm{yr}$. Here projections of future changes in rainfall extremes in the MASP region were derived from the Eta-CPTEC $40 \mathrm{~km}$ regional model nested in the HadCM3 global model, with 4 available realizations of the global model for the A1B emissions scenario to the end of the 21st century. Trends were assessed for significance using the nonparametric Mann-Kendall test. Projections, based on percentiles and on the number of days with rainfall above a certain limit, suggested: (a) an increase in total precipitation, (b) an increase in heavy precipitation and in the contribution to total precipitation from more intense rainfall events, and (c) the possibility of longer dry periods separating days with intense rain in the MASP region. The trends were stronger and more significant in the second half of the 21st century. We are aware that dynamical downscaling may not provide information at the weather station level and that climate modeling does not resolve all uncertainties. However, we believe that this exercise enables climate assessments that, in time, can be used for general public information.
\end{abstract}

KEY WORDS: Metropolitan Area of São Paulo - Heavy precipitation - Climate modeling · Climate change

Resale or republication not permitted without written consent of the publisher

\section{INTRODUCTION}

A changing climate leads to changes in the frequency, intensity, spatial extent, duration, and timing of weather and climate extremes, and can result in extremes of unprecedented magnitude. Many weather and climate extremes are the result of natural climate variability, and even if there were no anthropogenic changes in climate, a wide variety of natural weather and climate extremes would still occur (Seneviratne et al. 2012).
As suggested by Song et al. (2011), changes in the total amount of rainy-season precipitation are manifested in different ways - i.e. by variations in the number of wet days, by variations in precipitation intensity, or by both. Studying both factors makes possible a better understanding of the individual contributions to changes in precipitation during the rainy season. These changes are generating concern over the environmental security of urban areas, particularly in cities where people and assets are concentrated, and in high-risk areas where vulnerable 
populations live. Many impacts of climate change in cities, especially in the short and medium term, will be felt in the form of enhanced variability and changing frequency of extreme events, some of them with the potential to trigger natural disasters (Rosenzweig et al. 2011).

The effects of intense rainfall and floods (which can occur in any season in Southeast Brazil) vary according to location. In recent years, heavy or extreme precipitation events have had considerable effects on society, especially through flash floods and landslides - associated with intense, but often brief, rainfall events - which are among the most destructive extreme events (e.g. the January 2011 landslide in the highlands region of Rio de Janeiro which killed $>1000$ people; Marengo \& Alves 2012).

Within most cities in Latin America, climate risks fall disproportionately on low-income groups who occupy high-risk sites, and have the least adequate provision of protective infrastructure and services and no formal tenure over the land they occupy (Romero Lankao 2011). Urban areas and megacities in Latin America are hotspots of vulnerability to floods, heat waves, landslides, and other hazards that climate change is expected to aggravate. The Metropolitan Area of the city of São Paulo (MASP), located in southeastern Brazil, is considered one of the 10 largest urban conglomerates in the world and is classified as a megacity, occupying an area of $8051 \mathrm{~km}^{2}$, with approximately 20 million inhabitants (IBGE 2011).

A large number of studies focusing on precipitation changes during the last 40 to $50 \mathrm{yr}$ have detected changes in precipitation extremes worldwide, associated with increasing mean temperatures (e.g. Alexander et al. 2006, Beniston et al. 2007, Easterling et al. 2008, Caesar et al. 2011, Seneviratne et al. 2012). Southeastern Brazil shows an increase in the frequency of intense rain events above a given threshold or percentile level, and possible increases in dryness (Alexander et al. 2006, Haylock et al. 2006, Marengo et al. 2009a,b,c, 2011, Silva Dias et al. 2012, Donat et al. 2013, Skansi et al. 2013). On seasonal time scales, Donat et al. (2013) shows that in southeastern South America there was a strong increase in extreme precipitation between 1951 and 2010 across the seasons, particularly during December to May.

In the state of São Paulo, Dufek \& Ambrizzi (2008) performed an analysis of various indices of rainfall extremes and dryness during the period 1950-1999, and found statistically significant trends associated with a wetter climate, as well as an increase in drier conditions as shown by the positive consecutive dry days (CDD) trends. A significant increase in total precipitation was associated with an increase in the frequency of very heavy precipitation days. Their results indicated that intense precipitation is becoming concentrated on a few days and spread over the period separated by longer dry spells.

Changes in rainfall extremes have been identified in various sectors of the MASP (Conti 1979, Xavier et al. 1994, Pereira Filho et al. 2004, Dufek \& Ambrizzi 2008, Marengo et al. 2009a, Nobre et al. 2011, Silva Dias et al. 2012). In fact, while the numbers of days with rainfall $>50 \mathrm{~mm}$ in the city of São Paulo were almost nil during the 1950s, they occurred between 2 and 5 times per year by 2000-2010 (Nobre et al. 2011). Furthermore, a recent study by Pinto et al. (2013) shows a significant increase in thunderstorm activity in the city of São Paulo after 1951. This may be increasing the impacts on vulnerable people living in areas where a risk of flash flooding and landslides exists.

Studies on the effects of urbanization on climate in the MASP have been performed using various regional models (Freitas \& Silva Dias 2005, Freitas et al. 2007, Mourão 2010), and the simulations suggest that urbanization of areas originally covered with natural vegetation may cause temperature to increase by about $3.5^{\circ} \mathrm{C}$ or more, with more hot days, which can therefore affect convective rainfall.

The assessment of global or regional climate model performance with respect to extremes, particularly at the regional scale, is still limited by the very rarity of extreme events, which makes evaluation of model performance less robust than in the case of average climate. Evaluation is further hampered by incomplete data on the historical frequency and severity of extremes, particularly for variables other than temperature and precipitation, and also for specific regions. Understanding past changes in the characteristics of such events, including recent increases in the intensity of heavy precipitation events over a large part of the MASP, is critical for reliable projections of future changes.

Therefore, in this study, observed trends in rainfall extremes in the MASP region were investigated over the last 60 yr. Furthermore, to detect possible changes in rainfall extremes up to the year 2100, assessments of regional climate change projections were made, derived from downscaling of the UK HadCM3 global model, using the Eta CPTEC regional model with a horizontal resolution of $40 \times 40 \mathrm{~km}$ (Chou et al. 2011, Marengo et al. 2011). The analyses covered the short, medium, and long term up to 2100. Detailed analyses were performed for the MASP 
region (shown in Fig. 1). More details on observed trends in rainfall extremes in the MASP region can be found in Silva Dias et al. (2012), and the references quoted therein.

\section{METHODOLOGY}

\subsection{Observational data sets}

We used the data from the meteorological station of the University of São Paulo, referred to as IAG-Agua Funda $\left(23.65^{\circ} \mathrm{S}, 46.61^{\circ} \mathrm{W}, 800 \mathrm{~m}\right.$ above sea level), with data available since 1933. The station is in southern São Paulo city, but located in the center of a park, and therefore separated from human development and heavy urbanization. Various studies (Marques dos Santos et al. 2006, Nobre et al. 2011) have documented annual rainfall increases of $395 \mathrm{~mm}$ over the period 1936-2005, and this value has been updated by Silva Dias et al. (2012) to be $425 \mathrm{~mm}$ from 1933 to 2010. These changes may be linked to changes in the surrounding vegetation due to urbanization effects, to air pollution in the MASP, or to changes in rainfall extremes. Long-term changes in time series of extremes for this and other stations in the MASP area are described in G. O. Obregon et al. (unpubl.), and will be used to complement the analyses of observed rainfall extreme trends in the MASP area.

\subsection{Models used}

In this study we used the projections of climate produced by the Eta-CPTEC $40 \mathrm{~km}$ regional model nested in the UK Met Office Hadley Centre coupled ocean-atmosphere global model HadCM3. We ran a 4-member regional model ensemble in order to address some of the uncertainties inherent in any model simulation. The boundary conditions were taken from 4 members of the HadCM3 'Perturbed Physics Ensemble' experiment in which the standard model structure is used, and perturbations are introduced to the physical parameterization schemes to produce variants of the same model. These are not changes in the physical parameterizations among the 4 members; rather, the changes are on parameter settings for the same parameterization, and the subset was selected according to its performance in the realistic simulation of the current climate, while sampling parameter space widely (Murphy et al. 2007). The model was run for the SRES A1B emissions scenario to the end of the 21st century.

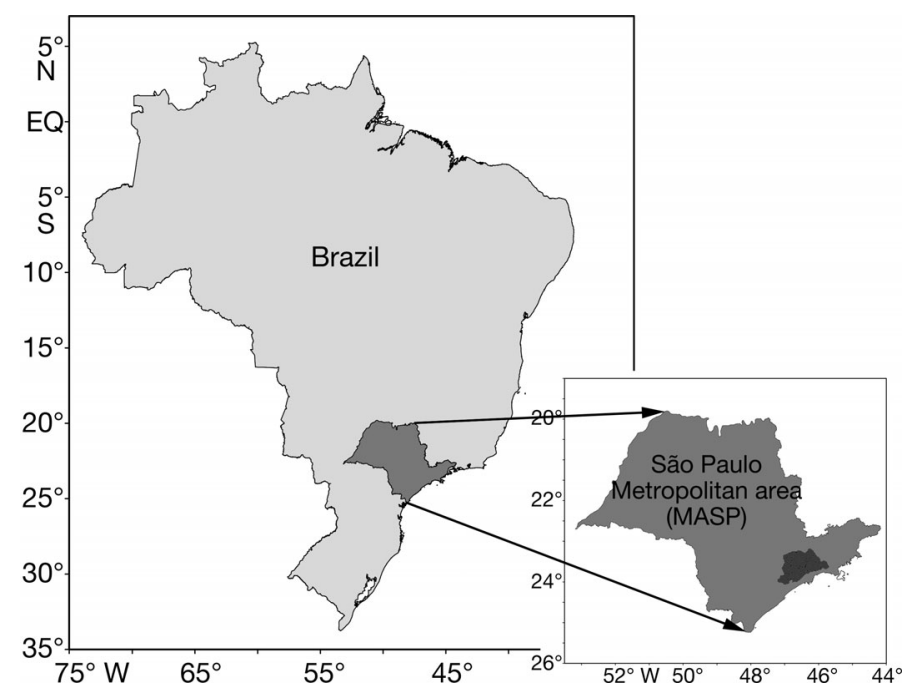

Fig. 1. Location of the Metropolitan Area of São Paulo, MASP (dark gray)

The regional climate was simulated using the EtaCPTEC regional model, and some modifications were made to Eta-CPTEC to be adapted for climate change runs by using sea-surface temperature derived from monthly means from the HadCM3. The inclusion of $\mathrm{CO}_{2}$ in the Eta-CPTEC was made possible through the work by Fels \& Schwarzkopf (1975), in which new vertical profiles of temperature compatible with increases in $\mathrm{CO}_{2}$ of 100 and $200 \%$ were developed. Alterations in the Eta-CPTEC original code were made to allow the $\mathrm{CO}_{2}$ concentration to vary in accordance with the HadCM3. At decadal time scales, a linear interpolation was performed in order to generate annual values of $\mathrm{CO}_{2}(\mathrm{Chou}$ et al. 2011)

Recent studies by Chou et al. (2011) and Marengo et al. (2011) used the same 4 members from the HadCM3 ensemble as boundary conditions passed to Eta-CPTEC, for the present (1961-1990) and the future (2010-2100), respectively. Although only 1 emission scenario (SRES A1B) was available, for each of the 4 members, the differences in model sensitivity could be regarded as providing plausible future climates representative of different emissions pathways. In the present study we used the 4 members, thus effectively sampling a range of possible futures.

For this study, we used the 1961-1990 simulations of climate from the Eta-CPTEC model nested in these boundary conditions of the HadCM3 for present climate. The analysis of future changes in various indices for rainfall extremes was carried out over the time slices 2010-2040, 2041-2070 and 2071-2100 relative to the baseline climatology of 1961-1990. 


\subsection{Indices of extremes and trend analysis}

The indices for the use of short-term extreme climate events in this study were defined by Frich et al. (2002). These indices sample the tail of a reference period distribution, and were calculated for 19611990 (the present) and the 3 time slices for the 4 members of the Eta CPTEC-HadCM3 run.

From a total of 27 available indices, we used 5 of them:

- Annual total precipitation (PRCPTOT): total annual accumulated precipitation (in $\mathrm{mm}$ ),

- Consecutive dry days (CDD): the annual maximum number of consecutive days when daily precipitation was $<1 \mathrm{~mm}$ (in days),

- Maximum 5 d precipitation (R5D): the annual maximum consecutive $5 \mathrm{~d}$ precipitation total that could lead to flooding (in $\mathrm{mm}$ ),

- Extreme rainfall (R95P): the annual total PRCPTOT when precipitation is $>95$ th percentile of the 19611990 daily precipitation distribution (in $\mathrm{mm}$ ),

- Wet days (R10, R20, R30, R50, R80): the number of days in a year with precipitation $>10,20,30,50$, $80 \mathrm{~mm}$, respectively.

In addition, we defined another index:

- Light rain (R5): the number of days with precipitation between 0.1 and $5 \mathrm{~mm}$.

None of these indices represent extremely rare events, for which the computation of significant trends could be a priori hampered by the small sample sizes.

The direction and statistical significance of trends in the indices was determined using the nonparametric Mann-Kendall test (Haylock et al. 2006, Dufek \& Ambrizzi 2008), a test that has been extensively used to determine trends in hydrological records. This statistic measures the relative ordering of all possible pairs of data points, with the year used as the independent variable and the extreme index as the dependent variable.

Trends in observed and modeled indices of extremes are assessed using a linear fit. Trend analysis describes the underlying smooth long-term changes with time series in climate, and is an important and popular tool for better detection of climate variations and change. The simplest and most frequent type of change is the linear trend (monotonic change), a continuous increase (positive) or decrease (negative) over time. In some cases, natural factors of inherent variability in hydrologic or climate time series can lead to substantial deviations from linearity (Burn 1994) (e.g. in cyclical or highly varying data and in non-linear events), making it difficult to differentiate between natural variability and trends (Askew 1987), compounded by the fact that a trend is meaningful only with sufficient length of the time series. We admit the limitations of the current trend analyses, and suggest the need for the study of non-linear trends in future studies, but we limited this study to linear trends. Furthermore, linear trends still provide a simple way of discriminating the overall long-term climate change and of quantifying its magnitude over time.

\section{RESULTS}

\subsection{The present}

The analysis of long-term variability in extremes at individual stations in the MASP region is shown in G. O. Obregon et al. (unpubl.). In the present study, we provide a summary of observed tendencies of indices of rainfall extremes at the IAG-Agua Funda station, to identify how extremes of rainfall have varied from the 1930 s to 2010.

Fig. 2 shows that PRCPTOT and R95P (and, to lesser degree, R5D) have been increasing steadily, albeit with pronounced interannual variability. A similar tendency was observed in R10-R80.

Table 1 shows a summary of observed changes of rainfall indices in the city of São Paulo as measured at the IAG-Agua Funda station. In agreement with Silva Dias et al. (2012), assuming a linear fit in the observed trends, we found that the most significant trends were for increases in PRCPTOT and R95P.

Light precipitation (R5) shows a slightly negative trend to 2010. Furthermore, between 1930 and 1950, R5 was higher than R10), while this was reversed in 1980-2010, suggesting a reduction in light rain and an increase in moderate and intense precipitation events. In this regard, Xavier et al. (1994) analyzed rainfall variability at the same IAG USP station during the period 1933-1986, and found an increase in rainfall intensity in all seasons, but particularly in February and May. They also found a year-round reduction of light rainfall (between 0.1 and $5 \mathrm{~mm}$ $\mathrm{d}^{-1}$ ), along with the fact that the contribution of days with rainfall $>30 \mathrm{~mm}$ in the MASP region (most particularly during February and May) increased during 3 periods: 1933-1950, 1951-1968, and 1969-1986.

Observations at the IAG USP Agua Funda station showed that during the last $20 \mathrm{yr}$ R30 has varied between 10 and $15 \mathrm{~d}$, as compared to 5 to $12 \mathrm{~d}$ in 1940-1960. Urban effects can be particularly important in explaining the extremes of daily rainfall in the 



Fig. 2. Time series of indices of extremes at the IAG USP Agua Funda meteorological station, in the MASP area $\left(23.65^{\circ} \mathrm{S}, 46.61^{\circ} \mathrm{W}, 800 \mathrm{~m}\right.$ above sea level). R10 to R80: number of days with rainfall $>10$ to $80 \mathrm{~mm}$, respectively; R5: number of days with rainfall $<5 \mathrm{~mm}_{i}$ PRCPTOT: total annual precipitation; CDD: consecutive dry days; R5D: maximum 5 d precipitation; R95P: extreme rainfall. Trends are statistically significant at 95\% percent level for PRECTOT and R95P
Table 1. Summary of observed changes of rainfall indices in the city of São Paulo as observed at the IAG-Agua Funda station during the period 1933-2010. As in Silva Dias et al. (2012), we assume a linear fit to the observed trends. Significance was assessed using the Mann-Kendall test. S: significant; NS: non-significant

\begin{tabular}{|lcc|}
\hline Index & $\begin{array}{c}\text { Observed } \\
\text { trend }\end{array}$ & $\begin{array}{c}\text { Significance } \\
(5 \%)\end{array}$ \\
\hline R5 & $-0.12 \mathrm{~d} \mathrm{yr}^{-1}$ & $\mathrm{NS}$ \\
PRCPTOT & $+5.2 \mathrm{~mm} \mathrm{yr}^{-1}$ & $\mathrm{~S}$ \\
R95P & $+3.5 \mathrm{~mm} \mathrm{yr}^{-1}$ & $\mathrm{~S}$ \\
R5D & $+0.6 \mathrm{~mm} \mathrm{yr}^{-1}$ & $\mathrm{NS}$ \\
R10 & $+0.20 \mathrm{~d} \mathrm{yr}^{-1}$ & $\mathrm{NS}$ \\
R20 & $+0.22 \mathrm{~d} \mathrm{yr}^{-1}$ & $\mathrm{NS}$ \\
R30 & $+0.65 \mathrm{~d} \mathrm{yr}^{-1}$ & $\mathrm{NS}$ \\
R50 & $+0.29 \mathrm{~d} \mathrm{yr}^{-1}$ & $\mathrm{NS}$ \\
CDD & $-0.01 \mathrm{~d} \mathrm{yr}^{-1}$ & $\mathrm{NS}$ \\
\hline
\end{tabular}

condensation nuclei, leading to the division of condensed water vapor among a larger number of condensation nuclei with less water per nucleus, and thus with a larger probability of the resulting smaller droplets remaining in the atmosphere and not precipitating. During the wet season the growth of the urban heat island and the role of air pollution included in the microphysics was found to largely explain the increase in rainfall extremes in the MASP area during 1933-2010 (Silva Dias et al. 2012).

Similar situations have been detected in most subtropical and tropical monsoon climate regions of southeastern China during 1960-2000, where the number of days with rain $>50 \mathrm{~mm}$ showed a slightly positive trend, while precipitation days with light rain (<10 mm) decreased (Song et al. 2011, Liu et al. 2011).

\subsection{The future}

the frequency of light rain events shown in Fig. 2 has been linked to warming in the MASP region (Lombardo 1985, Xavier et al. 1994, Oliveira 1991). The city of São Paulo is influenced by a sea breeze, andhas a tendency for nights that are warmer than the 1961-1990 climatology, relative humidity is reduced and thus condensation is hampered. This is somewhat aggravated in polluted air, which contains more
We acknowledge the fact that there are a number of factors that limit the ability to evaluate how well models simulate indices by comparison against observed indices, particularly at the station level. One of the main drawbacks of dynamical downscaling is that it does not provide information at the point (i.e. weather station) scale, because that is a scale at which the re- 
gional climate model (RCM) parameterizations would not work. RCMs provide area-averaged precipitation, which reduce the magnitude of extremes (Haylock et al. 2006) compared with point values, and this is noted in analyzing rainfall extremes above $50 \mathrm{~mm} \mathrm{~d}^{-1}$ (R50). However, we believe that this exercise allows the detection from some trend analyses of increases or decreases of a variable that eventually can be used to inform stakeholders and the general public, even though uncertainties may be still high.

Fig. 3 shows the time series of observed anomalies at the IAG USP Agua Funda station, along with simulated (1961-1990) and projected anomalies of some indices of rainfall extremes at a grid box near the IAG USP meteorological station. The statistical significance, assessed using a Mann-Kendall test for the baseline 1961-1990 period, showed that the simulated trends for all indices were not statistically significant at the $5 \%$ level.

For projections through 2100 (Fig. 3), the MannKendall test suggested that all tendencies for R10, R5D, R95P, and PRCPTOT were statistically significant at the $5 \%$ level. Projections showed positive tendencies PRCPTOT and R10, as well as weak positive trends in CDD, and negative trends in R5.

While the observed trends reflected not only the increase in the concentration of greenhouse gases (GHG), but also the effects of urbanization and landuse changes, the projected trends considered only increases in the concentration of GHG, because neither the global nor regional models accounted for the land-use and urbanization effect, for both the present and future.

For the MASP and nearby regions, Fig. 4 shows the ensemble of the projections of total rainfall and the indices of rainfall extremes for the time slices 2010$2040,2041-2070$, and 2071-2100, relative to 19611990 for the ensemble of the 4 members. Statistical significance was assessed using the Mann-Kendall test, and the areas where significance at the $5 \%$ level was reached are shown with signs (+ or -) inside the curves. The PRCPTOT maps show the increase in total annual rainfall up until the end of the 21st century, and this increase reached significance at the $5 \%$ level to the southeast, west, and northeast of the MASP by 2041, and then by 2090 the change started to become more intense, reaching up to $+150 \mathrm{~mm}$ over the MASP, and more than $+300 \mathrm{~mm}$ to the north and southwest of the MASP region. Similar behavior was observed in the R10 index, where changes between +2 and $+6 \mathrm{~d}$ over the MASP area by 2041 and 2070 gave way to significant changes of between +6 and $+10 \mathrm{~d}$ by 2041 and $>+10 \mathrm{~d}$ by 2071 .
In the MASP region and to the north, the frequency and intensity of heavy precipitation appeared to be increasing, with changes that were stronger and significant from the middle (2041-2070) to the end of the century (2071-2100) as shown by the R5D and R95P indices. The R5D index also suggested an increase in extreme rainfall events in the MASP region and especially toward the north, suggesting higher occurrences of flood events in vulnerable areas of the state and city of São Paulo. There was a tendency for a decrease in R5, by 2 to $6 \mathrm{~d}$ short term (2010-2040) and by 10 to $14 \mathrm{~d}$ long term (2071-2100). The CDD index also suggested a significant increase in the frequency of dry spells, mainly to the north of the MASP region, suggesting that, while rainfall extremes may be more frequent and intense in the future, this would be in the form of intense rainfall concentrated over a few days, with longer dry spells in between rainfall events.

The spread among members as measured by the standard deviation (SD) of the ensemble mean can be considered an indicator of uncertainty. Fig. 5 shows the ensemble of model-derived indicies of rainfall extremes, the magnitude of the spread as shown by the SD was larger to the northeast and to the southwest of the MASP region, where the increase in rainfall was more intense and significant. This pattern was also detected in projections for rainfall extremes, days with intense and light rain, and consecutive dry days. Figs. $4 \& 5$ suggest that the projected changes, mainly in 2041-2070 and 2071-2100, were intense and significant, especially in the northern part of the MASP region, and, to the southwest and northeast of this region, the spread among members was also large, suggesting that the projected changes were still subject to uncertainties. The spread in the regional model climatology suggested that, for this time period, the final climate showed stronger dependence on the regional model internal characteristics, given similar large-scale conditions provided by the driver model.

The indices based on percentiles or number of days with rainfall above a certain limit indicated an increase in the intensity and frequency of rainfall extremes in the MASP region and to the northeast. The projected changes shown in Figs. 3 \& 4, derived from the Eta-HadCM3 runs, were comparable in tendency with those derived from the IPCC AR4 global models shown by Tebaldi et al. (2006), Junquas et al. (2012), and Seneviratne et al. (2012), particularly after 2040, and from other downscaling experiments (Marengo et al. 2009a,b,c, Nuñez et al. 2009) for southeastern South America, where the MASP region was located. 
Fig. 3. Time series of anomalies of the indices: (A) PRCPTOT, (B) R10, (C) R5D, (D) R95P, (E) R5, and (F) CDD-abbreviations in Fig. 2. Red: observations at the IAG USP station (1933-2010); black: ensemble of the 4 members from the Eta CPTEC-HadCM3 model for simulations (1961-1990) and projections (2071-2100); blue: 20 yr moving average; green shading: individual runs. Anomalies are relative to the respective long-term mean for 1961-1990 for observed and projected indices
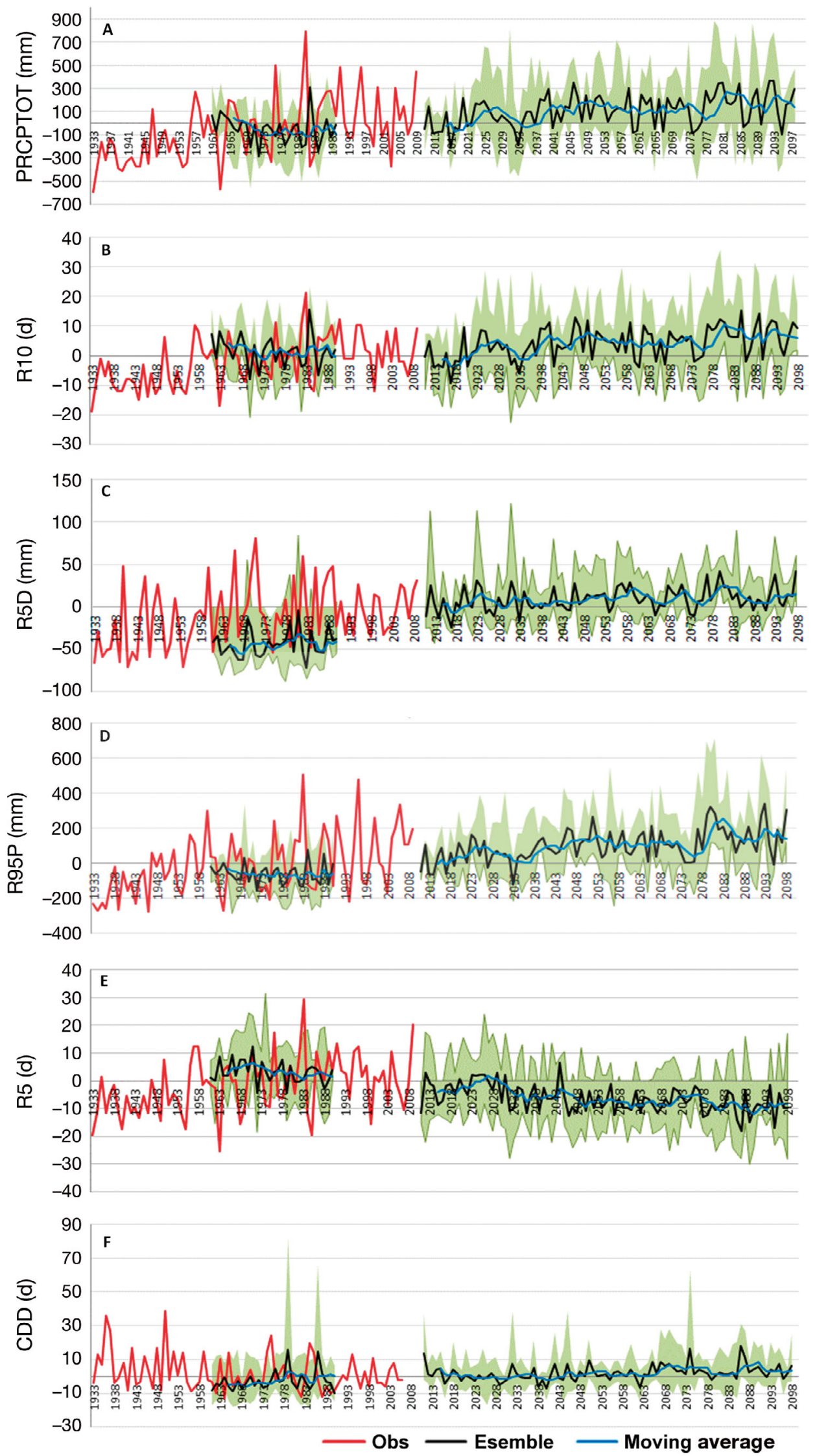


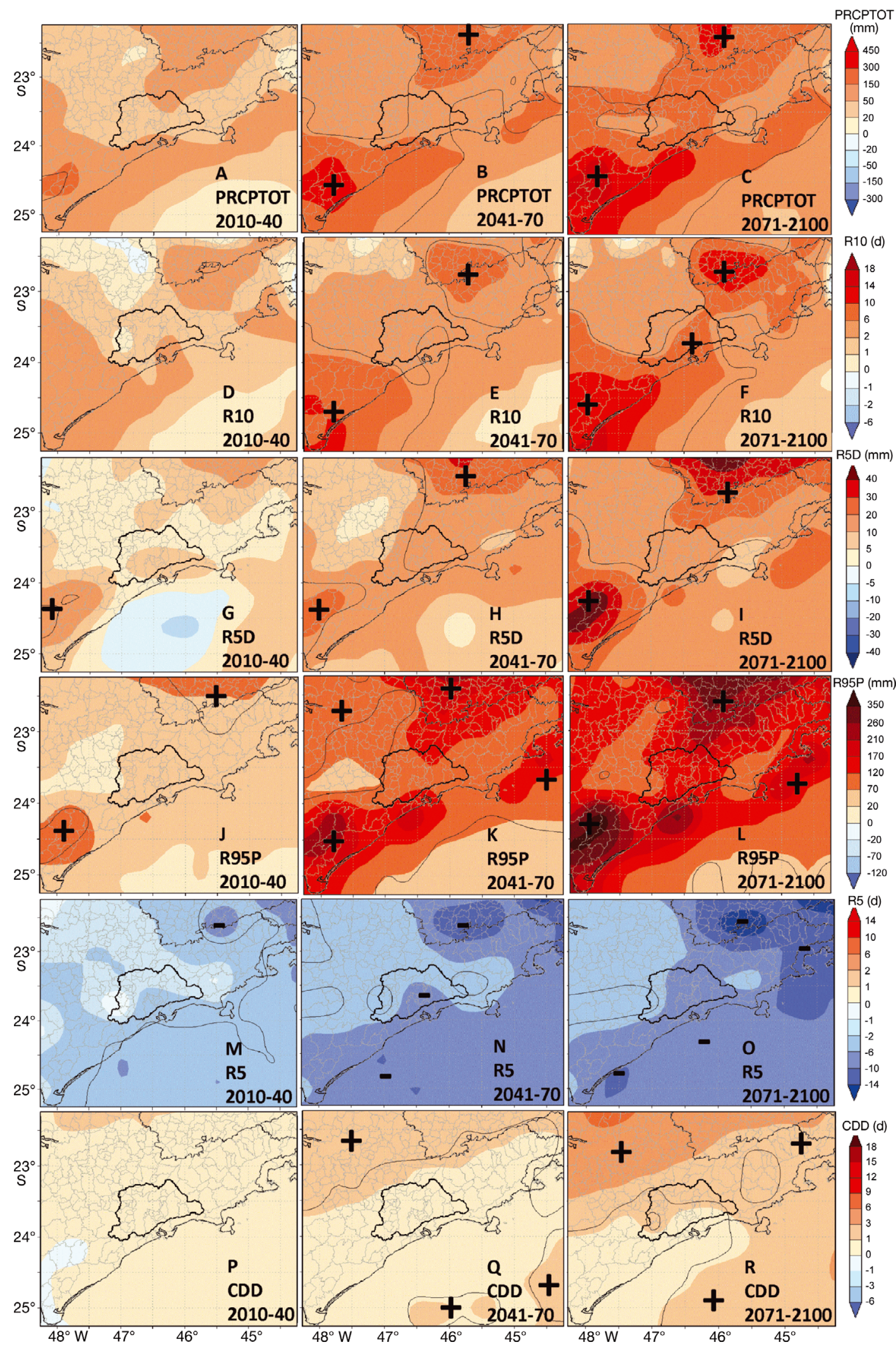

Fig. 4. Maps of changes of the indices PRCPTOT, R10, R5D, R95P, R5, and CDD for the northeastern part of the state of São Paulo, based on the ensemble mean of the 4 runs. Thick black line: MASP region. Changes are for the 2010-2040, 2041-2070, and 2071-2100 time slices relative to 1961-1990. Statistical significance at the 5\% level was assessed by the Mann-Kendall test; dashed lines (with signs): areas where significance was reached 


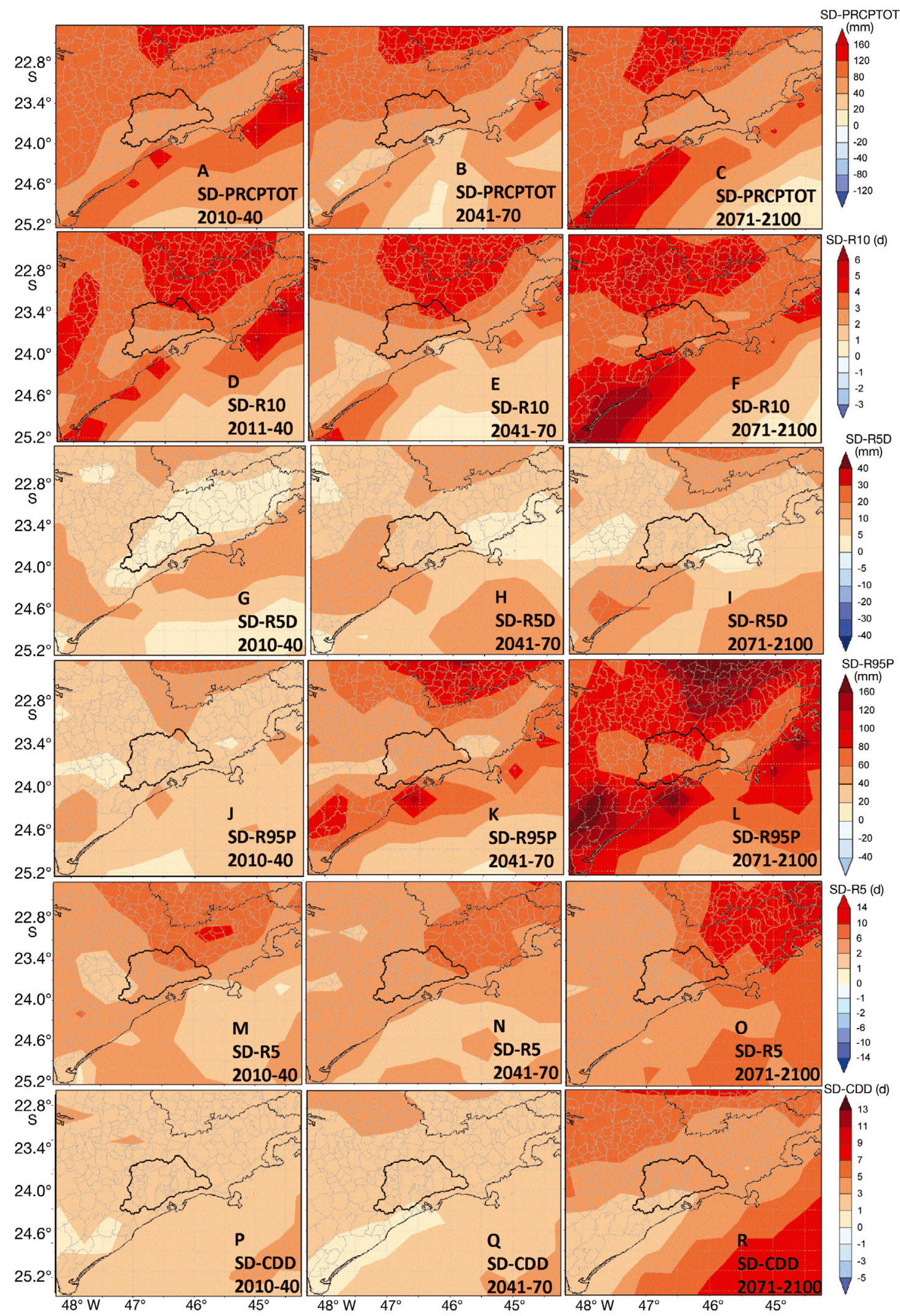

Fig. 5. Maps of standard deviations (SD) of changes of the indices PRCPTOT, R10, R5D, R95P, R5, and CDD for the northeastern part of the state of São Paulo, based on the ensemble mean of the 4 runs. Thick black lines: MASP region. Changes are for the 2010-2040, 2041-2070, and 2071-2100 time slices relative to 1961-1990 
Table 2 summarizes in a qualitative way the observed and projected trends for indices of rainfall and extremes for the 1961-1990 base-line, and for 3 time slices for the future as derived from the Eta-HadCM3 $40 \mathrm{~km}$ for the MASP region. Observations were from the IAG USP station, and the changes shown in the respective column were for the 1961-1990 period relative to the 1933-2009 long-term mean. The projected trends were comparable to those derived from global or regional models (e.g. Tebaldi et al. 2006, Vera et al. 2006, Marengo et al. 2009a,b, Nuñez et al. 2009) for southeastern South America and the MASP region until 2100. Since the above-mentioned studies were performed for the 2071-2100 time slice, it was possible to compare tendencies with those studies and also to assign higher confidence for the 2071-2100 period, as compared to the other 2 time slices.

\section{CONCLUSIONS}

Changes in rainfall extremes in the São Paulo region of southeastern Brazil to the end of the 21st century were assessed using a combination of observations and model projections. Observations from the meteorological station in the MASP showed an increase in total and heavy precipitation, and a decrease in light precipitation.

To assess projections of changes in rainfall extremes in the MASP region, we used an ensemble of 4 members of projections of climate based on the EtaHadCM3 models, for the SRES A1B emissions scenario to the end of the 21st century. The indices of extremes used in this study were those derived by Frich et al. (2002), with the addition of a light rainfall index R5 (number of days with precipitation $<5 \mathrm{~mm}$ ). Trends were assessed for significance using the nonparametric Mann-Kendall test.

Projections based on percentiles or number of days with rainfall above a certain threshold indicated an increase in the intensity and frequency of total rainfall and heavy precipitation, as well as negative trends for light rain. In addition, weak positive trends in CDDs indicated an increase in dryness. This suggested an increase in total precipitation and in the contribution to total precipitation from more intense rainfall events, with the possibility of longer dry periods between days with intense rain, in the MASP region. The trends were more intense and significant in the second half of the 21st century. The changes in extremes, while intense and significant, showed considerable spread among members, suggesting that uncertainties were still high on these projections. This showed the influence of the large-scale conditions provided by the driver HadCM3 global model.

We are aware that dynamical downscaling may not provide information at a point (i.e. weather station) scale, because that is a scale at which RCMs parameterizations would not work. However, we believe that this exercise allows for trend analyses to detect increases or decreases in total and extreme rainfall and that this information can be used inform stakeholders and the general public, even though uncertainties in climate models may still be high. The strengths and weaknesses identified in the Eta should not be regarded as permanent defects, since the model is undergoing continuous improvement.

To avoid the impacts of extremes in both the present and future, cities will play an important role in assessing the vulnerability of their residents in order to implement adaptation measures. In the case of São Paulo, this includes urban floods and landslides resulting from intense rainfall where there is high exposure of the population to these hazards, with dozens of lives lost during the summer rainy season every year. If rainfall extremes and associated impacts on vulnerable populations in both urban and rural areas are expected to increase in frequency and intensity in the near future, then cities must be prepared with adaptation options so residents can cope with such consequences of climate change.

Since land use change, due to urbanization and the expansion of current cities, is not included in most projections of future climate, judicious studies combining land use changes and urbanization with GHG 
emission increases need to be implemented, with a resolution capable of representing local aspects of landscape and climate change in both the urban and suburban areas of megacities.

Acknowledgements. This work was partially funded by the UK Strategic Programme Fund (SPF) throughout the study 'Vulnerability of Brazilian megacities to climate change: metropolitan areas of São Paulo and Rio de Janeiro'. The Brazilian National Research Council (CNPq) supported J.A.M. Additional funding was provided by Rede-CLIMA; the National Institute of Science and Technology for Climate Change (INCT-CC); the FAPESP-Assessment of Impacts and Vulnerability to Climate Change in Brazil and Strategies for the Adaptation Options project (Ref. 2008/58161-1), FAPESP-NERC $C_{i}$ Impacts of climate extremes on ecosystems and human health in Brazil: PULSE-Brazil (Ref. 2011/518432); and the CLARIS-LPB project.

\section{LITERATURE CITED}

Alexander LV, Zhang X, Peterson TC, Caesar J and others (2006) Global observed changes in daily climate extremes of temperature and precipitation. J Geophys Res D 111(D05109), doi:10.1029/2005JE002462

Askew AJ (1987) Climate change and water resources. In: Solomon SI, Beran M, Hogg W (eds) The influence of climate change and climate variability on hydrologic regime and water resources, Vol 168. IAHS Publishers, Wallingford, p 421-430

Beniston M, Stephenson DB, Christensen OB, Ferro CAT and others (2007) Future extreme events in European climate: an exploration of regional climate model projections. Clim Change 81:71-95

Burn DH (1994) Hydrologic effects of climate change in west-central Canada. J Hydrol (Amst) 160:53-70

Caesar J, Alexander LV, Trewin B, Tse-ring K and others (2011) Changes in temperature and precipitation extremes over the Indo-Pacific region from 1971 to 2005. Int J Climatol 31:791-801

Chou SC, Marengo JA, Lyra AA, Sueiro G and others (2011) Downscaling of South America present climate driven by 4-member HadCM3 runs. Clim Dyn 38:635-653

Conti JB (1979) Crescimento Urbano e mudanças climáticas. Suplemento Cultural, o Estado de São Paulo, 9 September 1979, No. 149, Ano III, São Paulo

> Donat MG, Alexander LV, Yang H, Durre I and others (2013) Updated analyses of temperature and precipitation extreme indices since the beginning of the twentieth century: the HadEX2 dataset. J Geophys Res 118:20982118, doi:10.1002/jgrd.50150

> Dufek A, Ambrizzi T (2008) Precipitation variability in São Paulo State, Brazil. Theor Appl Climatol 93:167-178

Easterling DR, Anderson DM, Cohen SJ, Gutowski WJ and others (2008) Measures to improve our understanding of weather and climate extremes. In: Karl TR, Meehl GA, Christopher DM, Hassol SJ, Waple AM, Murray WL (eds) Weather and climate extremes in a changing climate. Regions of focus: North America, Hawaii, Caribbean, and U.S. Pacific Islands. A report by the U.S. Climate Change Science Program and the Subcommittee on Global Change Research, Washington, DC
Fels SB, Schwarzkopf MD (1975) The simplified exchange approximation: a new method for radiative transfer calculations. J Atmos Sci 32:1475-1488

Freitas ED, Silva Dias PL (2005) Alguns efeitos de áreas urbanas na geração de uma ilha de calor. Rev Bras Meteorol 20:355-366

> Freitas ED, Rozoff CM, Cotton WR, Silva Dias PL (2007) Interactions of an urban heat island and sea-breeze circulations during winter over the metropolitan area of São Paulo, Brazil. Boundary-Layer Meteorol 122:43-65

Frich P, Alexander LV, Della-Marta P, Gleason B, Haylock M, Klein Tank AMG, Peterson T (2002) Observed coherent changes in climatic extremes during the second half of the twentieth century. Clim Res 19:193-212

- Haylock MR, Peterson T, Abreu de Sousa JR, Alves LM and others (2006) Trends in total and extreme South American rainfall 1960-2000 and links with sea surface temperature. J Clim 19:1490-1512

IBGE (Instituto Brasileiro de Geografía e Estatística) (2011) Sinopse do Censo Demográfico 2010. Available at: www.ibge.gov.br/home/estatistica/populacao/censo2010/ calendario.shtm (accessed June 2013)

> Junquas C, Vera C, Li L, Le Treut H (2012) Summer precipitation variability over southeastern South America in a global warming scenario. Clim Dyn 38:1867-1883

Liu B, Xu M, Henderson M (2011) Where have all the showers gone? Regional declines in light precipitation events in China, 1960-2000. Int J Climatol 31:1177-1191

Lombardo, MA (1985) A ilha de calor nas metrópoles: o exemplo de São Paulo. HUCITEC, São Paulo

Marengo JA, Alves LM (2012) The intense rainfall and floods in Rio de Janeiro. In: State of the Climate in 2011. Bull Am Meteorol Soc 93:S175-S177

- Marengo JA, Jones R, Alves LM, Valverde MC (2009a) Future change of temperature and precipitation extremes in South America as derived from the PRECIS regional climate modeling system. Int J Climatol 29: 2241-2255

Marengo JA, Ambrizzi T, Rocha RP, Alves LM and others (2009b) Future change of climate in South America in the late XXI century: intercomparison of scenarios from three regional climate models. Clim Dyn 35:1089-1113. doi:10.1007/s00382-009-0721-6

Marengo JA, Rusticucci M, Penalba O, Renom M (2009c) An intercomparison of observed and simulated extreme rainfall and temperature events during the last half of the twentieth century: Part 2: historical trends. Clim Change 98:509-529. doi:10.1007/s10584-009-9743-7

Marengo JA, Chou SC, Kay G, Alves LM and others (2011) Development of regional future climate change scenarios in South America using the Eta CPTEC/HadCM3 climate change projections: climatology and regional analyses for the Amazon, São Francisco and the Paraná River Basins. Clim Dyn 38:1829-1848

Mourão CEF (2010) Simulação da interação entre processos de superfície e convecção na produção de chuvas intensas na região da Serra do Mar Paulista/Caroline Estéphanie Ferraz Mourão. Mestrado em Meteorologia, Instituto Nacional de Pesquisas Espaciais, São José dos Campos

Murphy JMB, Booth BBB, Collins M, Harris GR, Sexton DMH, Webb MJ (2007) A methodology for probabilistic predictions of regional climate change from perturbed physics ensembles. Philos Trans Soc RSoc Lond A 365: 1993-2028 
Nobre CA, Young AF, Saldiva P, Marengo JA and others (2011) Vulnerabilidade das megacidades brasileiras ás mudanças climáticas: região metropolitana de São Paulo. INPE/UNICAMP/USP/IPT/UNESP, São Paulo

Nuñez MN, Solman SA, Cabré MF (2009) Regional climate change experiments over southern South America. II. Climate change scenarios in the late twenty-first century. Clim Dyn 32:1081-1095

Oliveira S (1991) A Poluição do Ar e as Alterações Climáticas na Cidade de São Paulo. Revista POLIS, No. 3, dezembro, Ed. Especial ECO-92, São Paulo, p 37-44

Pereira Filho AJ, Barros MTL, Hallak R, Gandu AW (2004) Enchentes na Região Metropolitana de São Paulo: aspectos de mesoescala e avaliação de impactos. XIII CBMET, Fortaleza, CE (Anais CDROM)

Pinto O Jr, Pinto IRCA, Ferro MAS (2013) A study of the long-term variability of thunderstorm days in southeast Brazil. J Geophys Res Atmos 118, doi:10.1002/jgrd.50282

Romero-Lankao P (2011) Urban responses to climate change in Latin America: reasons, challenges and opportunities. Architectural Design 81:76-79

Rosenzweig C, Solecki WD, Hammer SA, Mehrotra S (2011) Urban climate change in context, Chap 1. In: Rosenzweig C, Solecki WD, Hammer SA, Mehrotra S (eds) Climate change and cities: first assessment report of the Urban Climate Change Research Network. Cambridge University Press, Cambridge, p 3-11

Seneviratne SI, Nicholls N, Easterling D, Goodess CM and others (2012) Changes in climate extremes and their

Editorial responsibility: Helmut Mayer, Freiburg, Germany impacts on the natural physical environment. In: Field CB, Barros V, Stocker TF, Qin D and others (eds) Managing the risks of extreme events and disasters to advance climate change adaptation. A special report of Working Groups I and II of the Intergovernmental Panel on Climate Change (IPCC). Cambridge University Press, Cambridge, and New York, NY, p 109-230

Silva Dias MAF, Dias J, Carvalho LMV, Freitas ED, Silva Dias PL (2013) Changes in extreme daily rainfall for São Paulo, Brazil. Clim Change 116:705-722

Skansi MM, Brunet M, Sigró J, Aguilar E and others (2013) Warming and wetting signals emerging from analysis of changes in climate extreme indices over South America, In Press. Global Planet Change 100:295-307

> Song Y, Achberger C, Linderholm HW (2011) Rain-season trends in precipitation and their effect in different climate regions of China during 1961-2008. Environ Res Lett 6:034025, doi:10.1088/1748-9326/6/3/034025

Tebaldi C, Haohow K, Arblaster J, Meehl G (2006) Going to extremes. An intercomparison of model-simulated historical and future changes in extreme events. Clim Change 79:185-211

- Vera C, Silvestri G, Liebmann B, González P (2006) Climate change scenarios for seasonal precipitation in South America from IPCC-AR4 models. Geophys Res Lett 33: L13707. doi:10.1029/2006GL025759

Xavier TMBS, Xavier A, Silva Dias MAF (1994) Evolução da precipitação diária num ambiente urbano: o caso da cidade de São Paulo. Rev Bras Meteorol 9:44-53

Submitted: August 15, 2012; Accepted: April 8, 2013 Proofs received from author(s): June 14, 2013 